Article type : Full Length

\title{
Reduced right ventricular output reserve in patients with systemic sclerosis and mildly elevated pulmonary arterial pressures
}

Christian Nagel, MD ${ }^{1,2,3, *}$; Alberto M. Marra, MD ${ }^{4 *}$; Nicola Benjamin, MSc ${ }^{1,3,}$; Norbert Blank, $\mathrm{MD}^{5}$; Antonio Cittadini, MD, $\mathrm{PhD}^{6}$; Gerry Coghlan, $\mathrm{MD}^{7}$; Oliver Distler, $\mathrm{MD}^{8}$; Christopher $\mathrm{P}$ Denton, $\mathrm{MD}^{9}$; Benjamin Egenlauf, $\mathrm{MD}^{1,3}$; Christoph Fiehn ${ }^{10}$; MD; Christine Fischer, Dr sc hum ${ }^{11}$; Satenik Harutyunova, MD ${ }^{1,3}$; Marius $M$ Hoeper, MD $^{12}$; Hanns-Martin Lorenz, MD ${ }^{5}$; Panagiota Xanthouli, $\mathrm{MD}^{1,3}$; Eduardo Bossone, $\mathrm{MD}, \mathrm{PhD}^{13}$ and Ekkehard Grünig, $\mathrm{MD}^{1,3}$,

* equally contributed

${ }^{1}$ Centre for Pulmonary Hypertension, Thoraxklinik at Heidelberg University Hospital, Heidelberg, Germany

${ }^{2}$ Lung Centre, Klinikum Mittelbaden, Baden-Baden Balg, Baden-Baden, Germany

${ }^{3}$ Translational Lung Research Center Heidelberg (TLRC), Member of the German Center for Lung Research (DZL), Heidelberg, Germany

${ }^{4}$ IRCCS SDN Research Institute, Naples, Italy

${ }^{5}$ Department of Rheumatology, University Hospital Heidelberg, Heidelberg, Germany

${ }^{6}$ Department of Translational Medical Sciences, University Federico II of Naples, Naples, Italy

${ }^{7}$ Cardiology Department, Royal Free Hospital, London, United Kingdom

${ }^{8}$ Department of Rheumatology, University Hospital Zurich, Switzerland

${ }^{9}$ Institute of Immunity and Transplantation, Centre for Rheumatology and Connective Tissue

Diseases, Royal Free Hospital, UK

${ }^{10}$ Practice for Rheumatology and Clinical Immunology, Baden-Baden, Germany

${ }^{11}$ Department of Human Genetics; University of Heidelberg; Heidelberg, Germany

${ }^{12}$ Department of Respiratory Medicine, Hannover Medical School, Hannover, Germany

${ }^{13}$ Cardiology Division, A. Cardarelli Hospital, Naples, Italy

\section{Corresponding Author:}

Ekkehard Grünig, MD

Centre for Pulmonary Hypertension

Thoraxklinik at Heidelberg University Hospital

Röntgenstrasse 1, D-69126 Heidelberg

Tel: +49-6221-396-8053, Fax: +49-6221-398-1209

E-Mail: ekkehard.gruenig@med.uni-heidelberg.de

This article has been accepted for publication and undergone full peer review but has not been through the copyediting, typesetting, pagination and proofreading process, which may lead to differences between this version and the Version of Record. Please cite this article as doi: 
Key words: systemic sclerosis, pulmonary hypertension, pulmonary arterial hypertension, haemodynamics, right ventricular reserve, pulmonary arterial compliance, right heart catheter

\section{Abstract \\ Objective:}

The objective of this prospective study was to evaluate right ventricular function and pulmonary arterial compliance ( $\mathrm{PAC}=$ stroke volume/pulse pressure) at rest and during exercise in patients with systemic sclerosis (SSc) with normal mean pulmonary artery pressures (mPAP) at rest, mildly elevated mPAP (mPAP 21-24mmHg) and manifest pulmonary hypertension $(\mathrm{mPAP} \geq 25 \mathrm{mmHg})$.

\section{Methods:}

Patients with SSc $(n=112)$ underwent clinical assessment and right heart catheterization at rest and during exercise and were divided into three groups according to their resting mPAP values: normal mPAP $(\leq 20 \mathrm{mmHg})$, mildly elevated mPAP $(21-24 \mathrm{mmHg})$ and pulmonary hypertension $(\mathrm{PH}, \mathrm{mPAP} \geq 25 \mathrm{mmHg}$ ). Results were compared between groups by ANOVA followed by post-hoc student's t-test.

\section{Results:}

Compared to patients with normal mPAP, patients with mildly elevated mPAP showed lower 6-minute-walking distance (6MWD; $p<0.008)$, lower cardiac index $(\mathrm{Cl})(\mathrm{p}=0.027)$ and higher PVR $(p=0.0002)$ during exercise and lower PAC at rest $(p=0.016)$ and different stages of exercise (25 Watts $p=0.033,75$ Watts $p=0.024)$.

\section{Conclusion:}

The results of this study suggest that impaired 6MWD in SSc-patients with mildly elevated mPAP might be caused by reduced PAC during exercise and reduced RV output reserve, presumably due to impaired coupling between the right ventricle and the pulmonary vasculature. These findings give further evidence for the clinical relevance of mildly elevated mPAP in patients with SSc. 


\section{Introduction}

The natural course of systemic sclerosis (SSc) is often complicated by the occurrence of pulmonary arterial hypertension $(\mathrm{PAH})(1,2)$. Patients with SSc-associated pulmonary arterial hypertension (SSc-PAH) have a lower survival rate compared to patients with idiopathic PAH $(\mathrm{IPAH})(3,4)$. The current haemodynamic definition of PAH is a resting mean pulmonary arterial pressure (mPAP) $\geq 25 \mathrm{mmHg}$ with elevated pulmonary vascular resistance (PVR) measured invasively by right heart catheter $(\mathrm{RHC})(7,8)$. A post-hoc analysis of the DETECT study on SSc-patients demonstrated that mildly elevated mPAP levels between 21 and 24 $\mathrm{mmHg}$ may represent an intermediate stage between normal mean pulmonary artery pressures $(<21 \mathrm{mmHg})$ at rest and manifest $\mathrm{PH}(9)$. Previous studies have shown that patients with mildly elevated mPAP have reduced exercise capacity, higher World Health Organisation $(\mathrm{WHO})$ functional class $(\mathrm{FC})(6,10)$, a high risk of developing manifest $\mathrm{PH}(11)$, and an impaired prognosis (1). However, the pathophysiological mechanisms underlying exercise intolerance in mPAP $21-24 \mathrm{mmHg}$ remain incompletely characterized.

In the current study we sought to evaluate the response of the right ventricle (RV) and pulmonary vasculature to exercise in three different groups of SSc-patients: mPAP $<21 \mathrm{mmHg}$ (normal resting mPAP), mPAP 21-24mmHg (formerly borderline-mPAP) and mPAP $\geq 25 \mathrm{mmHg}$ (manifest pulmonary hypertension). The question was whether these three groups show significant differences in right ventricular output reserve measured by an increase in cardiac index $(\mathrm{Cl})$ under exercise and pulmonary arterial compliance (PAC) measured by Swan-Ganz right heart catheter $(\mathrm{RHC})$ in routine clinical practice. RV output reserve is an emerging parameter which has shown to be of prognostic importance in patients with $\mathrm{PH}(15,16)$. For estimation of $\mathrm{PAC}$ (or capacitance) the measurement of stroke volume/pulse pressure (cardiac output/heart rate)/(systolicPAP-diastolicPAP) by RHC has been shown to be the most simple and practical method(17, 18). Furthermore RV output reserve and PAC may add crucial information to detect pulmonary vascular disease in this atrisk-population at an early stage $(13,14)$, which may also add to defining an indication for early targeted treatment. 


\section{Methods}

\section{Study population and design}

Patients affected by diffuse cutaneous SSc (dc-SSc) and limited cutaneous SSc (Ic-SSc) referred to our centre for the purpose of $\mathrm{PH}$ screening were prospectively and consecutively enrolled in this study between October 2012 and August 2016. The referring specialists were rheumatologists, cardiologists, pulmonologists and general practitioners. Definite diagnosis of SSc was confirmed by experienced rheumatologists (HL, NB, CF) according to the standard criteria of the American College of Rheumatology (19). Exclusion criteria were: inability to perform exercise $\mathrm{RHC}$, manifest $\mathrm{PH}$ confirmed by $\mathrm{RHC}$ prior to enrolment, receiving $\mathrm{PAH}$ therapy, renal insufficiency, systemic arterial hypertension with pressure values $>180 / 95 \mathrm{mmHg}$ at rest or $>230 / 120 \mathrm{mmHg}$ during exercise despite optimized medical treatment, previous evidence of clinically relevant left heart or lung disease or pregnancy.

All patients who were referred to our centre who did not fulfil exclusion criteria were entered into the study even if baseline Echo did not suggest $\mathrm{PH}$

All patients underwent a detailed clinical work-up including medical history, physical examination, electrocardiogram, 2-Dimensional-echocardiography at rest, lung function test, arterial blood gases, chest X-ray, functional class (FC) assessment, 6-minute walking distance (6MWD) under standardized conditions (20), laboratory testing including N-terminal pro brain natriuretic peptide (NTpro-BNP) levels, and RHC at rest and during exercise. 12lead electrocardiogram was performed in all patients (Hellige EK 512 P, Hellige, Germany). High resolution computed tomography (CT), ventilation/perfusion SPECT and CT angiography of the lungs were performed in all patients to diagnose/exclude patients with suspected chronic thromboembolic $\mathrm{PH}$, interstitial lung disease, or other respiratory diseases. Left heart catheterization was performed in all patients with suspected left heart disease. Manifest PH/PAH was diagnosed according to the current ERS/ESC-guidelines (8). 


\section{Definition of pulmonary hypertension (PH) and pulmonary arterial hypertension (PAH)}

$\mathrm{PH}$ and $\mathrm{PAH}$ were defined according to current ESC/ERS Guidelines (41). The haemodynamic definition for $\mathrm{PH}$ is $\mathrm{mPAP} \geq 25 \mathrm{mmHg}$, the definition for $\mathrm{PAH}$ (group 1 according to $\mathrm{WHO}$ classification) is $\geq 25 \mathrm{mmHg}$ and pulmonary arterial wedge pressure $(\mathrm{PAWP}) \leq 15 \mathrm{mmHg}$.

\section{Right heart catheter (RHC)}

SSc patients were consecutively referred to $\mathrm{RHC}$ in in order to screen this at-risk-population for manifest PH. Patients were examined on a variable load supine bicycle ergometer (model 8420; KHL Corp., Kirkland, Washington) by experienced investigators (CN, BE). The examination at rest was performed as previously described (1) in a supine position using the transjugular access with an 8F introducer set (MXI100, MEDEX, Smiths Group PLC, UK). Catheterization was done by triple-lumen 7F-Swan-Ganz thermodilution catheters by Edwards Lifesciences (REF:131F7, Edwards Lifesciences LLC, Irvine, CA, USA). After the hemodynamic measurement at rest, the supine position was changed to a $45^{\circ}$ position. The zero reference point for pressure recordings was set at midchest at the insertion of the 4th rib to the sternum in line with current recommendations(21) on the left atrial level. Zero levelling at $45^{\circ}$ position was performed at the intersection of the frontal plane at the midthoracic level, the transverse plane at the level of 4 th anterior intercostal space and the midsagittal plane on the left atrial level(22). The pulmonary vascular pressures (mPAP, PAWP) were averaged throughout three respiratory cycles. Cardiac output (CO) was measured at least in triplicate at rest and in duplicate at the end of each workload step during exercise by thermodilution with a variation of $<10 \%$ between the measured values. Exercise testing started at $25 \mathrm{~W}$ and was increased every 2 min for $25 \mathrm{~W}$ until symptom-limited exercise capacity was reached. The pulmonary vascular pressures (mPAP, PAWP), CO, heart rate and systemic blood pressure were measured at the end of each workload step(22) in line with current recommendations. 
Transpulmonary pressure gradient (TPG) was defined as the difference between mPAP and PAWP. PAC was calculated according the formula PAC=stroke volume/ pulse pressure; (CO/Heart rate)/(sPAP-dPAP). Right ventricular output reserve was defined and measured by the increase in cardiac index $(\mathrm{Cl})$ during incrementally increased exercise on the variable load supine bicycle ergometer compared to $\mathrm{Cl}$ at rest. All examinations and measurements were performed by the same experienced team $(\mathrm{CN}, \mathrm{BE}, \mathrm{SH})$. There were no complications.

\section{Transthoracic Doppler echocardiography at rest}

A complete left- and right-sided echocardiographic examination was done as described previously (14). Two-dimensional and colour-flow guided continuous-wave-Dopplerechocardiographic recordings at rest were obtained by experienced cardiac sonographers (CN, BE, SH, EG) using 3.6-4 MHz Duplex probes and conventional equipment (Vivid 7, GE Healthcare, Milwaukee, Wisconsin) at rest as described before (14). Pulmonary arterial systolic pressure (PASP) was estimated from peak tricuspid regurgitation jet velocities according to the equation: $\mathrm{PASP}=4(\mathrm{~V})^{2}+$ right atrial pressure, where $\mathrm{V}$ is the peak velocity (in $\mathrm{m} / \mathrm{s}$ ) of tricuspid regurgitation velocity (23). For all calculations the mean value of at least 3 tricuspid regurgitation velocity measurements was used. Right atrial pressure was estimated from characteristics of the inferior vena cava (24). If it was $<20 \mathrm{~mm}$ in diameter and decreased during inspiration $5 \mathrm{mmHg}$ were added, $\geq 20 \mathrm{~mm} 10 \mathrm{mmHg}$ were added, respectively.

\section{Ethics statement}

This study was conducted in accordance with Good Clinical Practice (GCP) and the current version of the revised Declaration of Helsinki (WMA Declaration of Helsinki). The ethics committee of the University of Heidelberg approved the study (Internal Ethics-Nr. S360/2009). The trial was registered in Clinicaltrials.gov (NCT01387035). Written informed consent was obtained from each patient prior to enrolment. 


\section{Statistical Methods}

Statistical analyses were conducted by two statisticians (CF, NB). Data are described as mean \pm standard deviation or number and \%, respectively. Patients were divided into three groups according to their resting mPAP values: normal mPAP (mPAP $\leq 20 \mathrm{mmHg}$ ), mildly elevated PAP (21-24 $\mathrm{mmHg})$ and manifest $\mathrm{PH}(\mathrm{mPAP} \geq 25 \mathrm{mmHg})$ (Figure 1). At rest, the three groups (normal mPAP, mildly elevated PAP and manifest $\mathrm{PH}$ ) were compared using analysis of variance (ANOVA) for quantitative variables and Chi square tests or exact Fisher Tests for categorical variables. The comparison of variables at rest and various levels of exercise or maximum level of exercise between the three groups were performed by ANOVA and mixed model ANOVA, respectively. If the ANOVA detected a significant difference, results were followed by post-hoc tests between normal and mildly elevated mPAP. Post-hoc analyses were conducted with student's t-tests. All tests were two-sided and a p-value of 0.05 was considered statistically significant. For post-hoc tests, statistical significance remained when $p$-values were $<0.016,<0.025$ and $<0.05$ for the first, second and third $p$ value when ordered from lowest to highest (Bonferroni-Holm correction).

Correlation of PAC at rest with 6MWD, $\Delta \mathrm{CO}$ and $\Delta \mathrm{Cl}$ was performed with Pearson correlation analysis.

All analyses have been performed using IBM SPSS 23 (SPSS Statistics V23, IBM Corporation, Somers, New York).

\section{Results}

\section{Clinical Characteristics}

We prospectively included 116 patients diagnosed with SSc. Four patients were excluded due to inability to perform $\mathrm{RHC}$. One patient refused $\mathrm{RHC}$ assessment due to painful skin. Three patients were not able to perform exercise $\mathrm{RHC}$ due to knee or hip problems. There 
were no complications. Thus, the final study group consisted of 112 patients with SSc (88 females, mean age $57 \pm 13$ years; 76 (67.9\%) with dc-SSc and 36 (32.1\%) with Ic-SSc (CREST Syndrome) (Table 1). According to RHC measurements at rest, 72 patients presented with normal mPAP $\leq 20 \mathrm{mmHg}$ (64.3\%), 14 with mildly elevated mPAP (21$24 \mathrm{mmHg} ; 12.5 \%)$ and 26 with manifest $\mathrm{PH}(\mathrm{mPAP} \geq 25 \mathrm{mmHg} ; 23.2 \%$, Figure 1).

The patients with $\mathrm{PH}$ had been newly diagnosed during the study. Most of them had been diagnosed at a relatively early stage of disease with an mPAP of $32.5 \pm 7.2 \mathrm{mmHg}$, a mean PVR of $326.2 \pm 188.3$ dynes $\cdot \mathrm{sec} \cdot \mathrm{cm}^{-5}$, and normal RV function at rest but with impaired WHO functional class and exercise capacity (Table 1). Out of the $26 \mathrm{PH}$-patients, 10 had $\mathrm{PAH}, 8$ $\mathrm{PH}$ due to left heart disease, and $8 \mathrm{PH}$ due to lung disease. Out of 14 patients with mildly elevated mPAP, two had concomitant coronary artery disease and five had concomitant interstitial lung disease.

\section{Comparison of clinical parameters}

The three groups (normal mPAP, mildly elevated mPAP, manifest $\mathrm{PH}$ ) differed in age, with

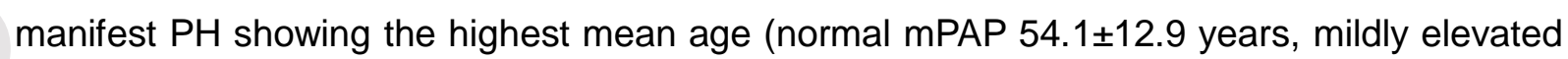
mPAP 58.1 \pm 11.0 years, manifest $\mathrm{PH} 66.7 \pm 9.3$ years; ANOVA $p<0.0001$; table 1 ). The Modified Rodnan Skin Score (MRSS) also differed between groups with normal mPAP 12.6 \pm 7.5 , mildly elevated mPAP $20.3 \pm 11.2$ and manifest $\mathrm{PH} 18.9 \pm 11.1$ (ANOVA $p=0.019$; table 1). There were no significant differences between patients with normal and mildly elevated mPAP with regards to sex, body size, duration of SSc and FC (Table 1). A comparable prevalence of coronary artery disease (CAD), mild SSc associated interstitial lung disease and arterial hypertension was found among the three different groups.

Although patients with mildly elevated mPAP had higher values of resting systolic blood pressure than those with normal mPAP $(138.6 \pm 16.9 \mathrm{mmHg}$ vs. $120.1 \pm 15.1 \mathrm{mmHg}, p=0.001)$, the systolic blood pressures during maximum workload did not significantly differ to patients with normal mPAP at rest $(156.9 \pm 22.8 \mathrm{mmHg}$ vs. $167.6 \pm 26.8 \mathrm{mmHg}, \mathrm{p}>0.05$; table 1$)$. Furthermore, PAWP during exercise did not significantly differ between groups. 


\section{Exercise capacity}

The mean 6MWD significantly differed (ANOVA $p<0.0001$ ) between the three groups with lowest walking distance in the manifest $\mathrm{PH}$ group ( $342 \pm 87$ meters), followed by patients with mildly elevated mPAP (396 \pm 87 meters) and highest walking distance in the normal mPAP group (474 \pm 79 meters; table 1$)$. Patients with mildly elevated mPAP had a significantly lower mean 6MWD compared to the group with normal haemodynamics $(p=0.008$; table 1$)$.

The difference in exercise capacity could also be seen in a different peak workload (ANOVA $\mathrm{p}<0.001)$ with highest peak workload in patients with normal mPAP $(76.7 \pm 21.9$ Watts), and

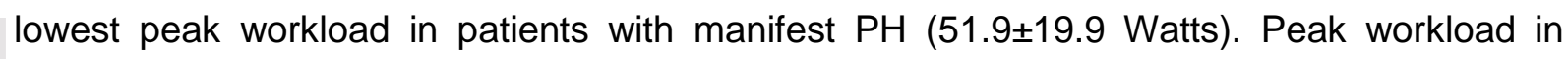
patients with mildly elevated mPAP was lower than in patients with normal mPAP (mildly elevated mPAP $62.5 \pm 25.5$ Watts; $p=0.033$ ). Patients with mildly elevated mPAP did not significantly differ from manifest $\mathrm{PH}$ in peak workload.

\section{Echocardiography}

The echo measurements showed no significant differences between patients with normal mPAP and mildly elevated mPAP regarding the size of the right atrium (RA) and the right ventricle $(\mathrm{RV})$ as well as systolic function measured by tricuspid annular plane systolic excursion (TAPSE) and estimated pulmonary arterial systolic pressure (PASP) assessed by transthoracic Doppler echocardiography (TDE) at rest. As expected patients with manifest $\mathrm{PH}$ revealed larger RA $\left(15.5 \pm 5.3 \mathrm{~cm}^{2}\right.$ vs. $\left.11.6 \pm 3.2 \mathrm{~cm}^{2}, \mathrm{p}=0.001\right)$ and $\mathrm{RV}$ area $\left(17.9 \pm 4.2 \mathrm{~cm}^{2}\right.$ vs. $\left.14.8 \pm 3.8 \mathrm{~cm}^{2}, p=0.001\right)$ as well as a thicker RV free wall $(7.5 \pm 1.3 \mathrm{~mm}$ vs. $6.5 \pm 1.2 \mathrm{~mm}$, $\mathrm{p}=0.004$ ) than patients with normal haemodynamics (table 1 ). Patients with mildly elevated mPAP at rest significantly differed from patients with manifest $P H$ in $R A$ area $(p=0.004), R V$ area $(p=0.003)$, sPAP $(p<0.001)$ and RV free wall $(p=0.016$; table 1$)$.

\section{Pulmonary haemodynamics at rest}

Patients with mildly elevated mPAP showed significantly higher mean pulmonary vascular resistance (PVR) at rest when compared with patients in the normal mPAP group $(179 \pm 32$ 
vs. $117 \pm 45$ dynes $\cdot \mathrm{sec} \cdot \mathrm{cm}^{-5} ; \mathrm{p}=0.001$ ) (Table 2 ) and higher transpulmonary pressure gradient (TPG) (12.7 \pm 3 vs. $7.5 \pm 2.6 \mathrm{mmHg}, \mathrm{p}<0.0001$; table 2). Values for PVR and TPG were significantly lower than in patients with manifest $\mathrm{PH}(\mathrm{p}=0.001$ and $\mathrm{p}<0.0001$, table 2$)$.

Mean PAWP were within normal range in patients with normal mPAP, mildly elevated mPAP and manifest $\mathrm{PH}$ (Table 2). No differences were found regarding right atrial pressures (RAP), as well as $\mathrm{RV}$ function at rest ( $\mathrm{CO}$ and $\mathrm{Cl}$ at rest, ns) among all groups (table 2).

\section{Pulmonary haemodynamics during exercise}

Patients with mildly elevated mPAP reached significantly higher mean (mPAP) and systolic pulmonary pressures (SPAP) at peak workload compared to patients with normal mPAP at rest $(37.4 \pm 6.3 \mathrm{mmHg}$ vs. $31.7 \pm 7.5 \mathrm{mmHg}, \mathrm{p}<0.0001)$. Patients with mildly elevated mPAP had a significantly lower increase in $\mathrm{CO}$ and cardiac index $(\mathrm{Cl})$ during exercise than patients with normal mPAP (peak Cl: $5.4 \pm 0.9$ vs. $6.3 \pm 1.8 \mathrm{l} / \mathrm{min} \cdot \mathrm{m}^{-2}, \mathrm{p}=0.027 ; \Delta \mathrm{Cl} 2.1 \pm 1.2$ vs. $3.3 \pm 1.5$ $\mathrm{I} / \mathrm{min} \cdot \mathrm{m}^{-2}, \mathrm{p}=0.006$ ) (table 2 ) and did not significantly differ from patients with manifest $\mathrm{PH}$.

$\mathrm{Cl}$ increases during exercise showed an almost congruent course in patients with mildly elevated mPAP and manifest PH up to the 50 Watts level (Figure 3). At 75 Watts, patients with mildly elevated mPAP patients showed a lower mean $\mathrm{Cl}$ increase than patients with manifest $\mathrm{PH}$ (ANOVA three groups $\mathrm{p}=0.009$; normal mPAP vs. mildly elevated mPAP $\mathrm{p}=0.005)$. Two patients with mildly elevated mPAP dropped their $\mathrm{Cl}$ during exercise, one at 25 and one at 50 Watts.

Patients with mildly elevated mPAP had a significantly higher TPG than patients with normal mPAP for values at rest, 25 Watts (both $p<0.001), 75$ Watts $(p=0.008)$ and showed a trend at 50 Watts $(p=0.059)$. The slope of TPG-increase during exercise was similar in patients with mildly elevated mPAP and normal mPAP.

PAC significantly differed between the three groups at rest and for each workload (each $\mathrm{p}$ 50.01). Patients with mildly elevated mPAP had a significantly lower PAC than patients with normal mPAP at rest $(p=0.016)$, as well as at $25(p=0.033)$ and $75(p=0.024)$ Watts (Figure 
4). PAC at rest significantly correlated with 6MWD ( $R=0.448, p<0.001), \Delta C O(R=0.227$, $\mathrm{p}=0.018)$ and correlated in trend with $\Delta \mathrm{Cl}(\mathrm{R}=0.178, \mathrm{p}=0.064)$.

\section{Discussion}

To the best of our knowledge, this is the first prospective study assessing RV output reserve and PAC in SSc-patients with mildly elevated mPAP in comparison to SSc patients with normal mPAP at rest and SSc-patients with manifest PH. The study showed that SScpatients with mildly elevated MPAP had normal Cl-values at rest but a reduced RV output reserve (defined as reduced $\mathrm{Cl}$ during exercise) and a reduced PAC compared to SSCpatients with normal mPAP at rest. Furthermore, the study revealed that SSc-patients with mildly elevated mPAP had higher PVR and TPG values than patients with normal mPAP. The impairment in RV function and pulmonary haemodynamics in patients with mildly elevated mPAP was associated with lower 6MWD and reduced peak exercise capacity compared to SSc patients with normal resting haemodynamics.

\section{Reduced RV output reserve in SSc-patients with mildly elevated mPAP}

Mean $\mathrm{RV} \mathrm{Cl}$ at rest was normal and did not differ between SSc-patients with normal or mildly elevated mPAP as previously described $(6,9,25)$. Even right heart size (mean right atrial and ventricular areas) measured by echocardiography were comparable between both groups. Thus, reduced RV output reserve, reduced PAC and higher PVR and TPG were the only hemodynamic parameters characterizing patients with mildly elevated MPAP and might be the pathophysiological underpinning of symptoms and reduced 6MWD/exercise capacity in these patients. These data suggest that exercise haemodynamics might be more sensitive to early RV dysfunction and vascular remodeling than resting haemodynamics.

RV output reserve and contractile reserve have been previously assessed in PAH patients using different methods and surrogate parameters: by invasive single-beat pressure-volume loop analysis(26-28), by stress Doppler-echocardiography (SDE) assessing the capability of patients to increase right ventricular systolic pressure during low-level exercise (14) and by 
echocardiographic strain during SDE (29). Although invasive single-beat pressure-volume loop analysis (30) is most likely the most sophisticated method to evaluate load-independent $\mathrm{RV}$ contractile reserve, its application can be dangerous for patients (stiff catheters), is too costly and complex for routine clinical practice and needs special equipment like conductance catheters with special software for online pressure-volume signals $(30,31)$ and transit-time ultrasonic flow probes (26). Therefore, the assessment of $\mathrm{Cl}$ increase during exercise by RHC using Swan-Ganz catheters has been used in PAH patients before $(15,16)$ and has been performed in this study. It seems to be a simple and useful method to measure RV output reserve.

\section{Reduced PAC in mildly elevated mPAP might indicate early vascular remodelling}

Whereas RV function was impaired during exercise only, PAC was already significantly reduced at rest and during all exercise levels in patients with mildly elevated mPAP and $\mathrm{PH}$ patients compared to patients with normal mPAP (Figure 4). Decreased PAC has been described in patients with idiopathic PAH (18) and was correlated with PH severity (32). In the present study, PAC was calculated from $\mathrm{RHC}$ data and it has been shown that PAC may detect early vascular disease in patients at risk for $\mathrm{PAH}$. This finding is in line with the elevated PVR and TPG in SSc patients with mildly elevated mPAP, which has already been found in a retrospective study of Kovacs et al 2014(6).

A reduced PAC increases RV pulsatile workload (33) and can lead to RV dysfunction and failure. $(34,35)$. PAC in PAH patients was a stronger predictor of prognosis and response to therapy than PVR alone (36-39).

\section{Myocardial function in SSc}

RV-PA uncoupling requires pulmonary vascular disease, reduced RV output reserve or both. SSc patients show myocardial involvement even in the absence of $\mathrm{PH}$. Hsu et al showed that patients with SSc who do not yet have resting PAH also exhibit abnormal sarcomere function due to reduced maximal calcium-activated tension and abnormal increase in calcium 
sensitivity (42). This depressed RV output reserve was also observed in manifest SSc-PAH compared to idiopathic $\mathrm{PAH}(43,28)$.

Beside a possible early pulmonary vascular disease indicated by reduced PAC, patients with mildly elevated pulmonary arterial pressures in SSc might also be affected by impaired myocardial contractility and might therefore be more affected in their exercise capacity, symptom load and quality of life.

\section{Overlap of mPAP $21-24 \mathrm{mmHg}$ and exercise induced $\mathrm{PH}$}

A resting mPAP $21-24 \mathrm{mmHg}$ is above the upper limit of normal but below the criteria of manifest $\mathrm{PH}$. Exercise $\mathrm{PH}$ is defined as $\mathrm{mPAP}>30 \mathrm{mmHg}$ and total pulmonary resistance (TPR) $>3$ WU (44). Lau et al showed a high overlap of mPAP 21-24mmHg with exercise PH with $86 \%$ in an at-risk population that was nearly twice as high as the group with mPAP $<21 \mathrm{mmHg}$ (45). This overlapping population was associated with worse functional capacity (45), increased progression to resting $\mathrm{PH}(11)$ and survival $(46,6)$. Oliveira et al found that exercise $\mathrm{PH}$ is most frequently found in mPAP $21-24 \mathrm{mmHg}$ and is reducing exercise capacity similar to resting $\mathrm{PH}$ (47). Our group with $\mathrm{mPAP}<21 \mathrm{mmHg}$ at rest fulfilled the criteria for exercise $\mathrm{PH}$ in 22 of 72 patients (30.6\%) vs. 11 of 14 patients $(78.6 \%)$ in the group with mPAP 21-24mmHg and is in line with the observation of Oliveira et al 2017. However, in our study, regression and correlation analysis revealed a significant correlation of PAC at rest with 6 MWD $(R=0.448, p<0.001), \Delta$ cardiac output $(R=0.227, p=0.018)$ and a trend with $\Delta$ cardiac index $(R=0.178, p=0.064)$ (Figure 2). This supports the hypothesis that PAC and $R V$ output reserve play another important role apart from exercise induced $\mathrm{PH}$ in exercise limitation of SSc patients with mPAP 21-24mmHg.

\section{Early treatment as future strategy}

The described changes in RV function during exercise and pulmonary haemodynamics at rest and during exercise in patients with mildly elevated mPAP raise the question whether targeted PAH therapy could enhance these impairments and would be justified in these 
patients. In our study, those patients with reduced PAC may already be manifesting increased resting PVR, which supports the idea of an early targeted treatment. In a pilot study, bosentan was safe and effective in patients with SSc and mildly elevated mPAP (40). Larger clinical trials with relevant outcome measures are needed to define the appropriate indication, safety and tolerability of early treatment.

\section{Study Limitations}

The study results may be influenced by the rather small sample size. As not all patients reached high workloads, we only reported values up to 75 Watts. Furthermore, the presentation of $\mathrm{Cl}$ and TPG for each workload is an approximation and may be distorted, as different peak workload levels were reached.

The method we used to calculate PAC may overestimate compliance as it does not account for blood flow from the pulmonary circulation into the capillary bed during systole (17). Thus, the true reduction of PAC in patients with mildly elevated mPAP may be even higher.

Patients with mildly elevated mPAP had higher values of resting systolic blood pressure than those with normal mPAP. However, the systolic blood pressure at peak workload was not significantly higher than that of the normal mPAP group. Furthermore, PAWP during exercise did not significantly differ between groups. This indicates that systemic blood pressures were no explanation for the reduced $\mathrm{Cl}$ increase during exercise in patients with mildly elevated mPAP.

Data from 2D echo under exercise would have been helpful for interpretation of the results but were not part of the initial protocol.

\section{Conclusion}

The results of this study suggest that impaired 6MWD and exercise capacity in SSc-patients with mildly elevated mPAP (and normal RV function at rest) might be caused by reduced PAC and reduced RV output reserve (reduced RV output during exercise). These findings 
give further evidence for mildly elevated mPAP reflecting an early stage of pulmonary vascular disease and RV dysfunction. Screening of SSc-patients using right heart catheter at rest and during exercise may lead to an identification of early pulmonary vascular disease. Further studies are needed to evaluate if it is useful to start PAH targeted medication in SSc patients with mildly elevated mPAP.

\section{Acknowledgements}

We would like to thank all patients who participated in the study. This work was the doctoral thesis of AMM.

\section{Figure legends}

\section{Figure 1}

The study flow-chart describes the study cohort, reasons for exclusion and group allocations.

\section{Figure 2}

Pearson's correlation analysis of PAC vs. 6MWD show a significant correlation of PAC at rest with 6MWD. mPAP-values $\leq 20 \mathrm{mmHg}$ are coded as green dots, mPAP $21-24 \mathrm{mmHg}$ are coded as orange triangles and $\mathrm{mPAP} \geq 25 \mathrm{mmHg}$ are coded as red squares.

\section{Figure 3}

The slope of $\mathrm{Cl}$ increase during exercise showed similar values for patients with mildly elevated mPAP and manifest $\mathrm{PH}$. For each stage, the $\mathrm{p}$-value of the respective ANOVA 
between the three groups is shown. At 75 Watts, mildly elevated mPAP patients had a significantly smaller increase in $\mathrm{Cl}$ than patients with normal mPAP (t-test $\mathrm{p}=0.005)$.

\section{Figure 4}

PAC significantly differed between groups for each workload level (ANOVA each $p \leq 0.01$ ). Patients with mildly elevated mPAP had a significantly lower PAC than patients with normal mPAP both at rest $(p=0.016)$, and during exercise at $25(p=0.033)$ and $75(p=0.024)$ Watts.

Table 1. Clinical characteristics of the overall study population and the three hemodynamic groups

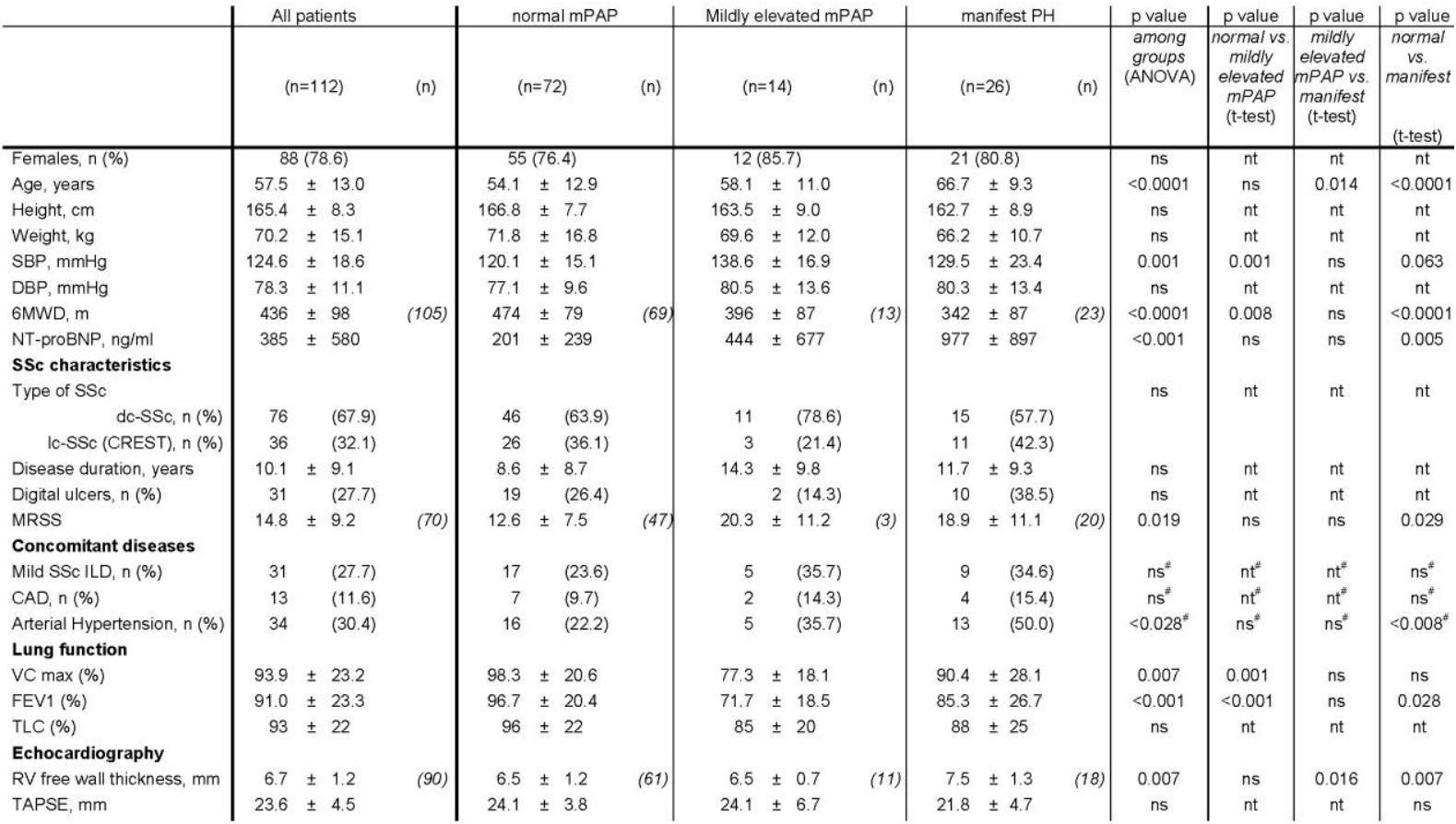

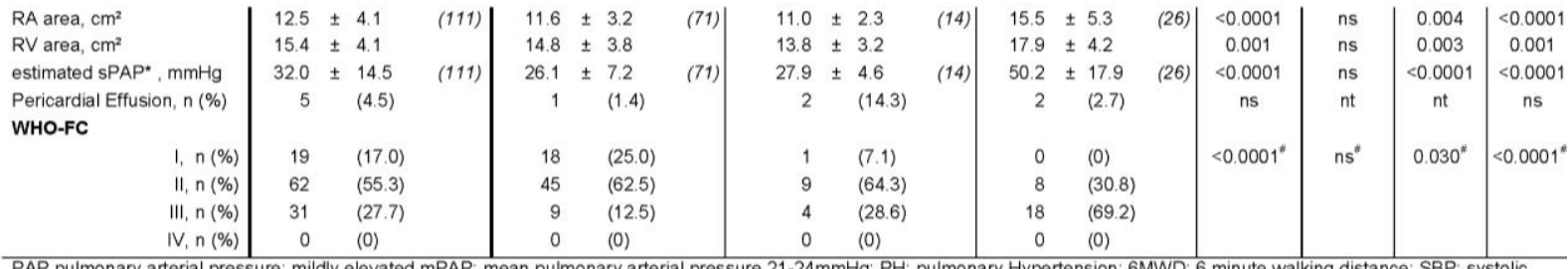

PAP pulmonary arterial pressure; mildly elevated mPAP: mean pulmonary arterial pressure 21-24mmHg; PH: pulmonary Hypertension; 6MWD: 6 minute walking distance; SBP: systolic blood pressure; DBP: diastolic blood pressure; SSc: systemic sclerosis; dc: diffuse cutaneous; Ic: limited cutaneous; MRSS: modified Rodnan Skin Score; SSc-lLD: Systemic sclerosis associated interstitial lung disease; CAD: Coronary Artery Disease; RV: Right Ventricle; TAPSE: tricuspid annular plane systolic excursion; RA: Right Atrium; sPAP: systolic pulmonary echocardiography. Values derive from the full sample of each group unless othenwise indicated

This article is protected by copyright. All rights reserved. 
Table 2. Resting and Exercise Haemodynamics

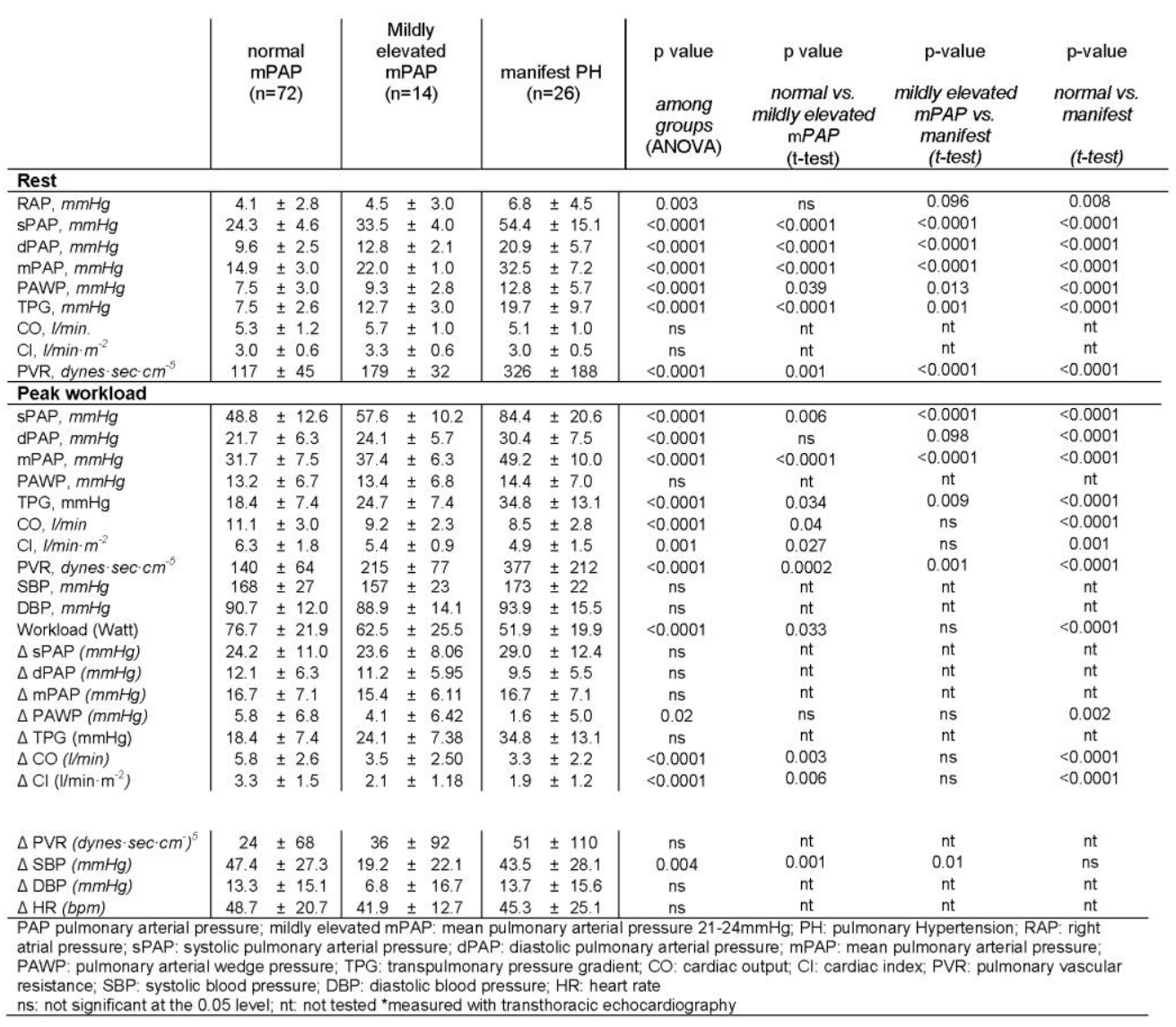

This article is protected by copyright. All rights reserved. 
Figure 1: study flow-chart

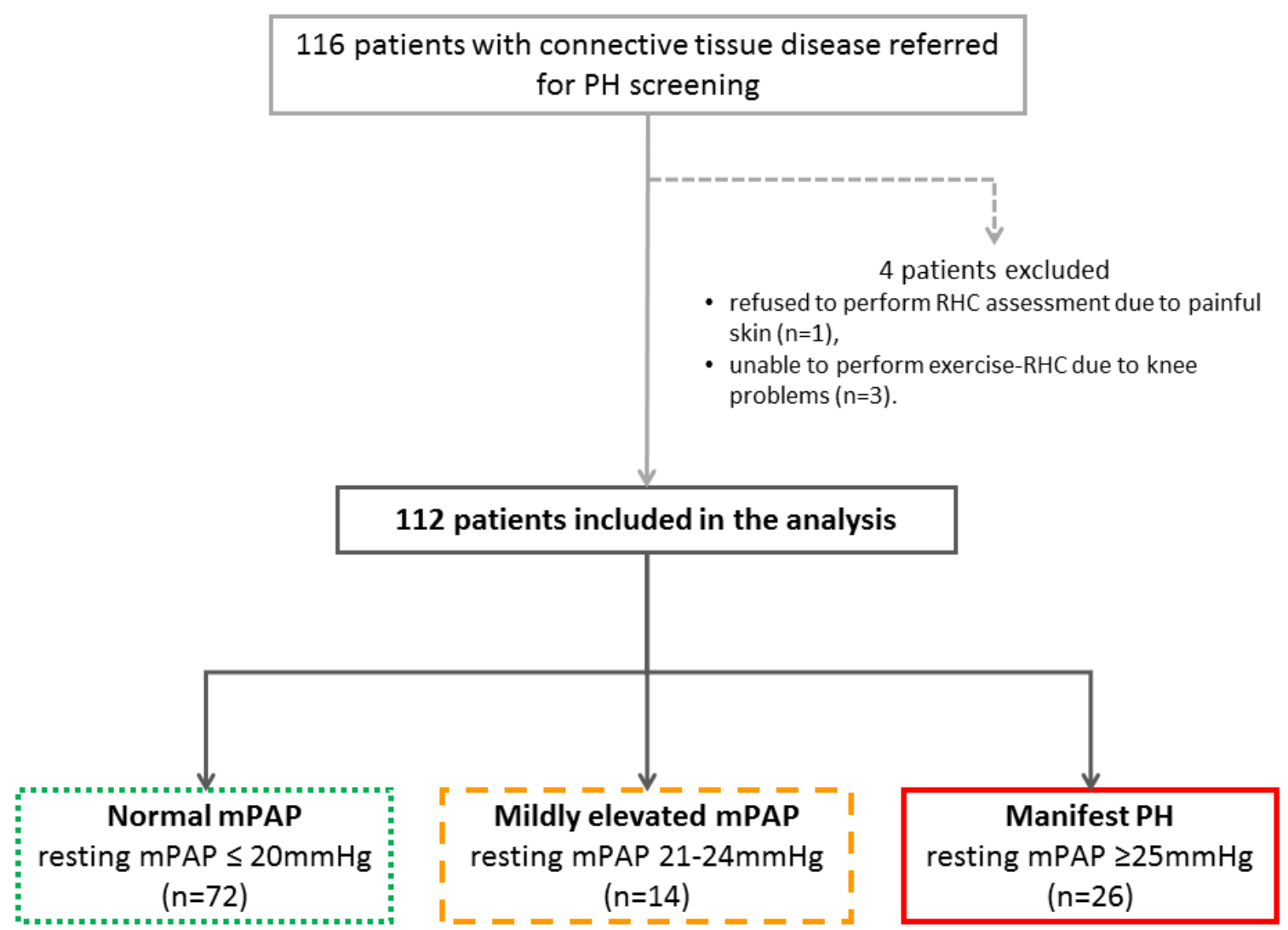

This article is protected by copyright. All rights reserved. 
Figure 2: Pearson's correlation analysis of PAC vs. 6MWD

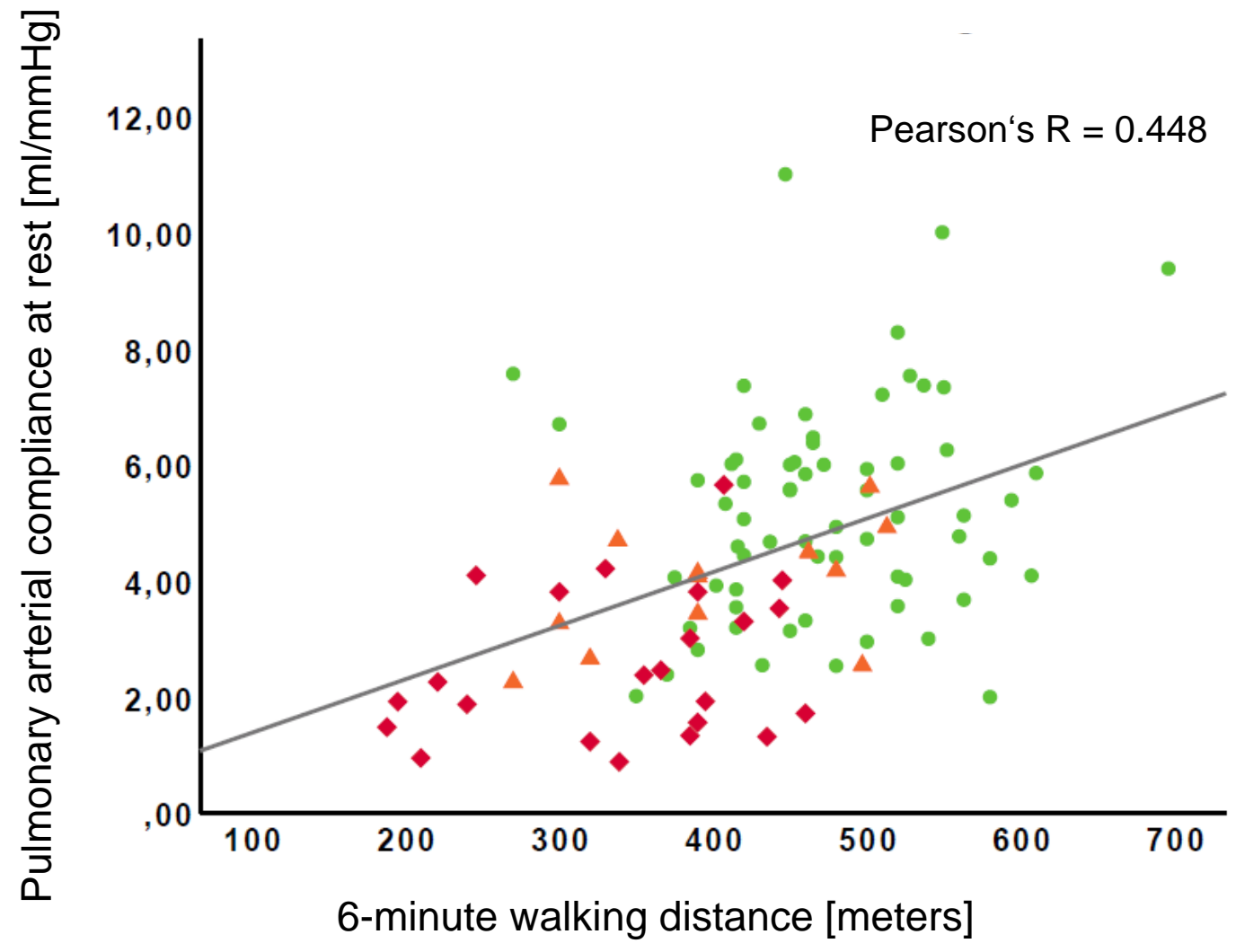

Figure 3: Cardiac Index increase over workload levels

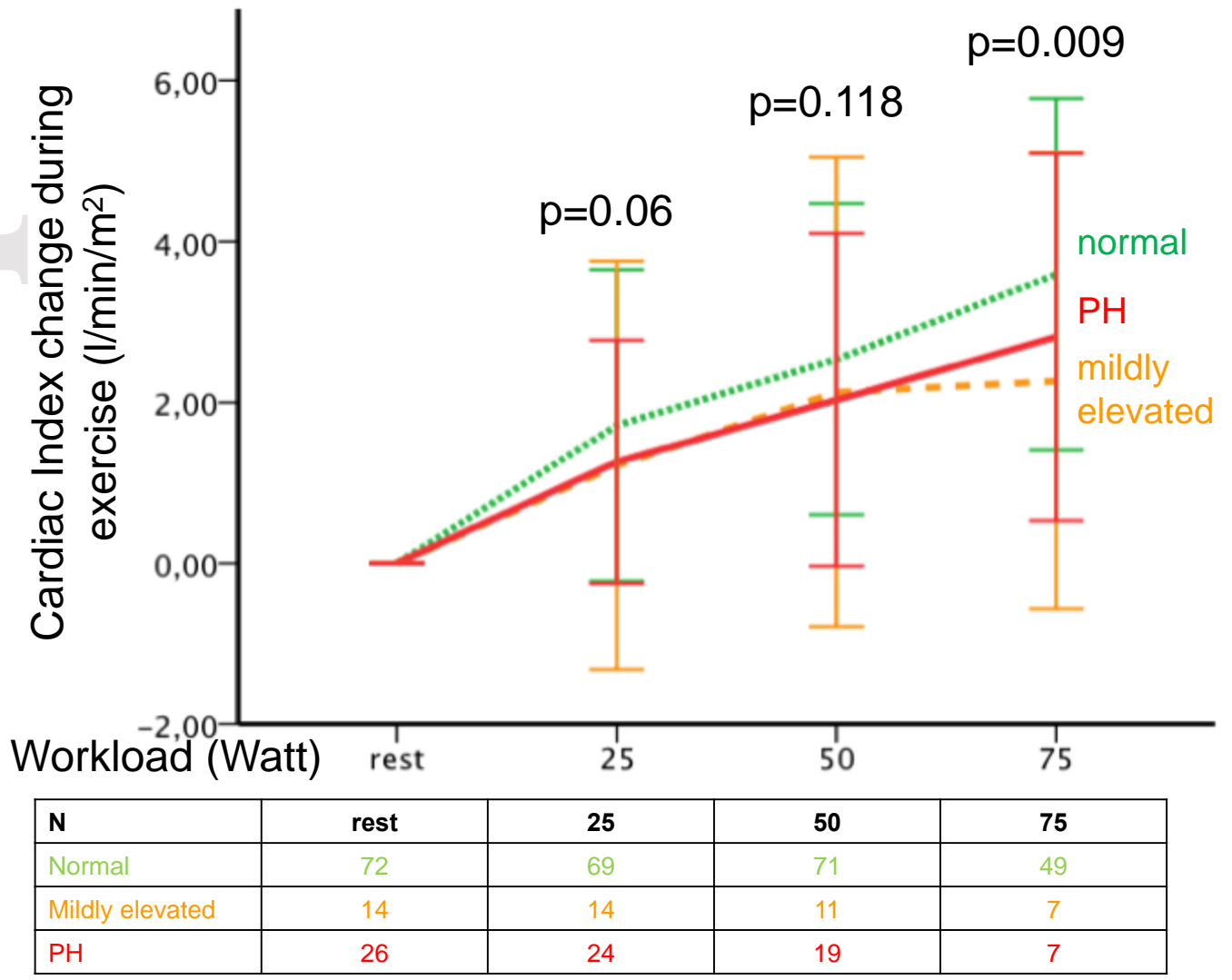

This article is protected by copyright. All rights reserved. 
Figure 4: PAC over workload levels

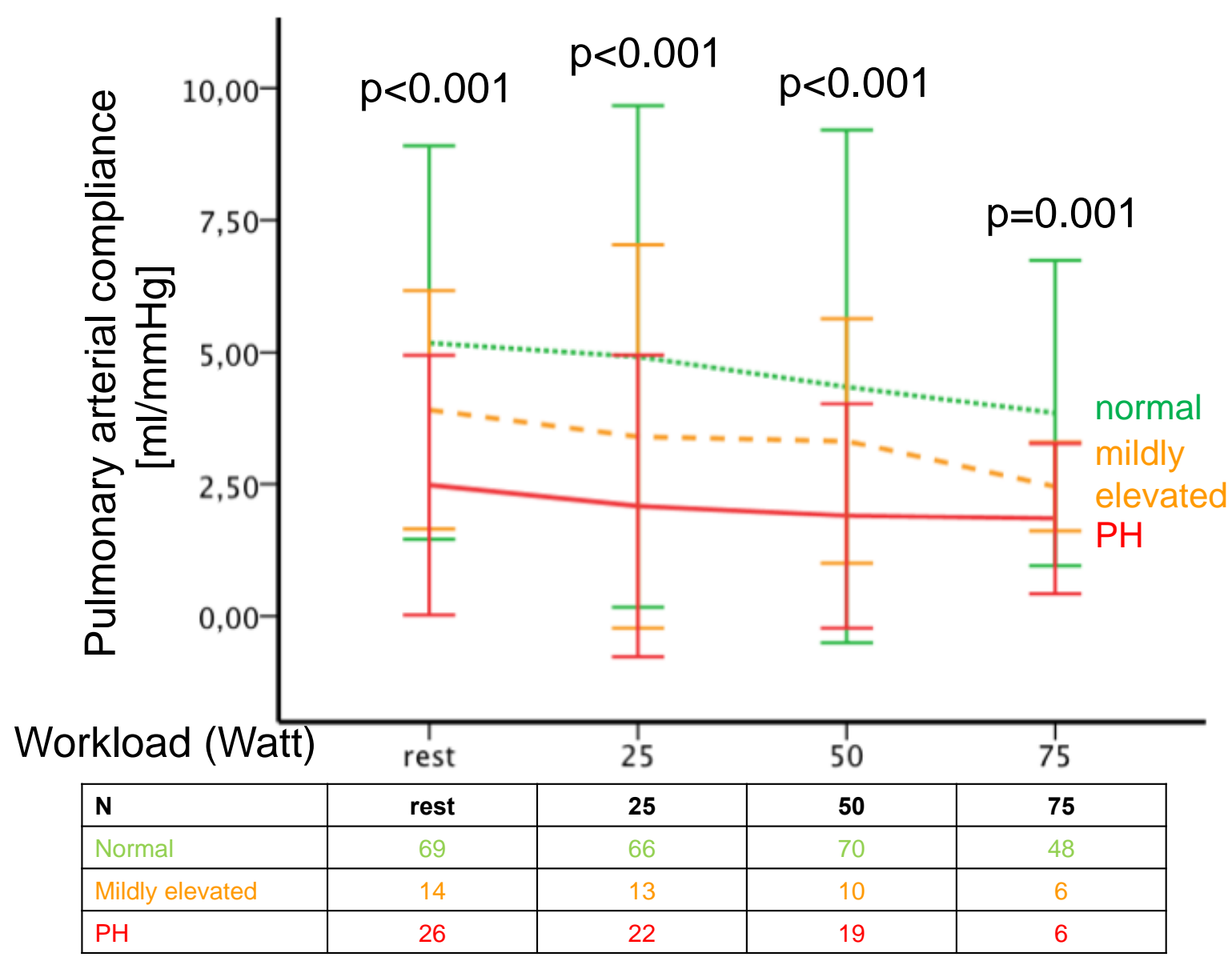

This article is protected by copyright. All rights reserved. 


\section{References}

1. Condliffe R, Kiely DG, Peacock AJ, Corris PA, Gibbs JS, Vrapi F, et al. Connective tissue diseaseassociated pulmonary arterial hypertension in the modern treatment era. Am J Respir Crit Care Med 2009;179:151-7.

2. Coghlan JG. Stress echocardiography and Cochin Risk Prediction Score for the prediction of pulmonary arterial hypertension in scleroderma: not yet ready for prime time. Arthritis Rheum 2013;65:2236-9.

3. Ngian GS, Stevens W, Prior D, Gabbay E, Roddy J, Tran A, et al. Predictors of mortality in connective tissue disease-associated pulmonary arterial hypertension: a cohort study. Arthritis Res Ther 2012;14:R213.

4. Lefevre G, Dauchet L, Hachulla E, Montani D, Sobanski V, Lambert M, et al. Survival and prognostic factors in systemic sclerosis-associated pulmonary hypertension: a systematic review and meta-analysis. Arthritis Rheum 2013;65:2412-23.

5. Steen V, Chou M, Shanmugam V, Mathias M, Kuru T, Morrissey R. Exercise-induced pulmonary arterial hypertension in patients with systemic sclerosis. Chest 2008;134:146-51.

6. Kovacs G, Avian A, Tscherner M, Foris V, Bachmaier G, Olschewski A, et al. Characterization of patients with borderline pulmonary arterial pressure. Chest 2014;146:1486-93.

7. Hoeper MM, Bogaard HJ, Condliffe R, Frantz R, Khanna D, Kurzyna M, et al. Definitions and diagnosis of pulmonary hypertension. J Am Coll Cardiol 2013;62:D42-50.

8. Galie N, Humbert M, Vachiery JL, Gibbs S, Lang I, Torbicki A, et al. 2015 ESC/ERS Guidelines for the diagnosis and treatment of pulmonary hypertension: The Joint Task Force for the Diagnosis and Treatment of Pulmonary Hypertension of the European Society of Cardiology (ESC) and the European Respiratory Society (ERS): Endorsed by: Association for European Paediatric and Congenital Cardiology (AEPC), International Society for Heart and Lung Transplantation (ISHLT). Eur Respir J 2015;46:903-75.

9. Visovatti SH, Distler O, Coghlan JG, Denton CP, Grunig E, Bonderman D, et al. Borderline pulmonary arterial pressure in systemic sclerosis patients: a post-hoc analysis of the DETECT study. Arthritis Res Ther 2014;16:493.

10. Kovacs G, Berghold A, Scheidl S, Olschewski H. Pulmonary arterial pressure during rest and exercise in healthy subjects: a systematic review. Eur Respir J 2009;34:888-94.

11. Valerio CJ, Schreiber BE, Handler CE, Denton CP, Coghlan JG. Borderline mean pulmonary artery pressure in patients with systemic sclerosis: transpulmonary gradient predicts risk of developing pulmonary hypertension. Arthritis Rheum 2013;65:1074-84.

12. Hoeper MM. Definition, classification, and epidemiology of pulmonary arterial hypertension. Semin Respir Crit Care Med 2009;30:369-75.

13. Lewis GD, Bossone E, Naeije R, Grunig E, Saggar R, Lancellotti P, et al. Pulmonary vascular hemodynamic response to exercise in cardiopulmonary diseases. Circulation 2013;128:1470-9.

14. Grunig E, Tiede H, Enyimayew EO, Ehlken N, Seyfarth HJ, Bossone E, et al. Assessment and prognostic relevance of right ventricular contractile reserve in patients with severe pulmonary hypertension. Circulation 2013;128:2005-15.

15. Blumberg FC, Arzt M, Lange T, Schroll S, Pfeifer M, Wensel R. Impact of right ventricular reserve on exercise capacity and survival in patients with pulmonary hypertension. Eur J Heart Fail 2013;15:771-5.

16. Chaouat A, Sitbon O, Mercy M, Poncot-Mongars R, Provencher S, Guillaumot A, et al. Prognostic value of exercise pulmonary haemodynamics in pulmonary arterial hypertension. Eur Respir J 2014;44:704-13.

17. Thenappan T, Prins KW, Pritzker MR, Scandurra J, Volmers K, Weir EK. The Critical Role of Pulmonary Arterial Compliance in Pulmonary Hypertension. Ann Am Thorac Soc 2016;13:276-84.

18. Jain P, Rao S, Macdonald P, Kotlyar E, Jabbour A, Hayward C, et al. Diagnostic Performance of Pulmonary Capacitance at Rest and During Exercise in Idiopathic Pulmonary Arterial Hypertension. Heart Lung Circ 2017.

This article is protected by copyright. All rights reserved. 
19. Preliminary criteria for the classification of systemic sclerosis (scleroderma). Subcommittee for scleroderma criteria of the American Rheumatism Association Diagnostic and Therapeutic Criteria Committee. Arthritis Rheum 1980;23:581-90.

20. Laboratories ATSCOPSfCPF. ATS statement: guidelines for the six-minute walk test. Am J Respir Crit Care Med 2002;166:111-7.

21. Kovacs G, Avian A, Pienn M, Naeije R, Olschewski H. Reading pulmonary vascular pressure tracings. How to handle the problems of zero leveling and respiratory swings. Am J Respir Crit Care Med 2014;190:252-7.

22. Kovacs G, Herve P, Barbera JA, Chaouat A, Chemla D, Condliffe R, et al. An official European Respiratory Society statement: pulmonary haemodynamics during exercise. Eur Respir J 2017;50. 23. Yock PG, Popp RL. Noninvasive estimation of right ventricular systolic pressure by Doppler ultrasound in patients with tricuspid regurgitation. Circulation 1984;70:657-62.

24. Ommen SR, Nishimura RA, Appleton CP, Miller FA, Oh JK, Redfield MM, et al. Clinical utility of Doppler echocardiography and tissue Doppler imaging in the estimation of left ventricular filling pressures: A comparative simultaneous Doppler-catheterization study. Circulation 2000;102:1788-94. 25. Coghlan JG, Denton CP, Grunig E, Bonderman D, Distler O, Khanna D, et al. Evidence-based detection of pulmonary arterial hypertension in systemic sclerosis: the DETECT study. Ann Rheum Dis 2014;73:1340-9.

26. Brimioulle S, Wauthy P, Ewalenko P, Rondelet B, Vermeulen F, Kerbaul F, et al. Single-beat estimation of right ventricular end-systolic pressure-volume relationship. Am J Physiol Heart Circ Physiol 2003;284:H1625-30.

27. Spruijt OA, Bogaard HJ, Heijmans MW, Lely RJ, van de Veerdonk MC, de Man FS, et al. Predicting pulmonary hypertension with standard computed tomography pulmonary angiography. Int J Cardiovasc Imaging 2015;31:871-9.

28. Hsu S, Houston BA, Tampakakis E, Bacher AC, Rhodes PS, Mathai SC, et al. Right Ventricular Functional Reserve in Pulmonary Arterial Hypertension. Circulation 2016;133:2413-22.

29. Chia EM, Lau EM, Xuan W, Celermajer DS, Thomas L. Exercise testing can unmask right ventricular dysfunction in systemic sclerosis patients with normal resting pulmonary artery pressure. Int J Cardiol 2016;204:179-86.

30. Latus H, Gummel K, Diederichs T, Bauer A, Rupp S, Kerst G, et al. Aortopulmonary collateral flow is related to pulmonary artery size and affects ventricular dimensions in patients after the fontan procedure. PLoS One 2013;8:e81684.

31. Wink J, de Wilde RB, Wouters PF, van Dorp EL, Veering BT, Versteegh MI, et al. Thoracic Epidural Anesthesia Reduces Right Ventricular Systolic Function With Maintained VentricularPulmonary Coupling. Circulation 2016;134:1163-75.

32. Sanz J, Kariisa M, Dellegrottaglie S, Prat-Gonzalez S, Garcia MJ, Fuster V, et al. Evaluation of pulmonary artery stiffness in pulmonary hypertension with cardiac magnetic resonance. JACC Cardiovasc Imaging 2009;2:286-95.

33. Vonk-Noordegraaf A, Haddad F, Chin KM, Forfia PR, Kawut SM, Lumens J, et al. Right heart adaptation to pulmonary arterial hypertension: physiology and pathobiology. J Am Coll Cardiol 2013;62:D22-33.

34. Rich S. Right ventricular adaptation and maladaptation in chronic pulmonary arterial hypertension. Cardiol Clin 2012;30:257-69.

35. Sutendra G, Michelakis ED. The metabolic basis of pulmonary arterial hypertension. Cell Metab 2014;19:558-73.

36. Chemla D, Lau EM, Papelier Y, Attal P, Herve P. Pulmonary vascular resistance and compliance relationship in pulmonary hypertension. Eur Respir J 2015;46:1178-89.

37. Mahapatra S, Nishimura RA, Oh JK, McGoon MD. The prognostic value of pulmonary vascular capacitance determined by Doppler echocardiography in patients with pulmonary arterial hypertension. J Am Soc Echocardiogr 2006;19:1045-50.

38. Medrek SK, Kloefkorn C, Nguyen DTM, Graviss EA, Frost AE, Safdar Z. Longitudinal change in pulmonary arterial capacitance as an indicator of prognosis and response to therapy and in pulmonary arterial hypertension. Pulm Circ 2017;7:399-408.

This article is protected by copyright. All rights reserved. 
39. Ghio S, D'Alto M, Badagliacca R, Vitulo P, Argiento P, Mule M, et al. Prognostic relevance of pulmonary arterial compliance after therapy initiation or escalation in patients with pulmonary arterial hypertension. Int J Cardiol 2017;230:53-8.

40. Kovacs G, Maier R, Aberer E, Brodmann M, Graninger W, Kqiku X, et al. Pulmonary arterial hypertension therapy may be safe and effective in patients with systemic sclerosis and borderline pulmonary artery pressure. Arthritis Rheum 2012;64:1257-62.

41. Galiè N, Humbert M, Vachiery JL, Gibbs S, Lang I, Torbicki A, et al. 2015 ESC/ERS Guidelines for the diagnosis and treatment of pulmonary hypertension. The Joint Task Force for the Diagnosis and Treatment of Pulmonary Hypertension of the European Society of Cardiology (ESC) and the European Respiratory Society (ERS). Eur Respir J 2015; 46(6): 1855-6.

42. Hsu S, Kokkonen-Simon KM, Kirk JA, Kolb TM, Damico RL, Mathai SC, et al. Right Ventricular Myofilament Functional Differences in Humans With Systemic Sclerosis-Associated Versus Idiopathic Pulmonary Arterial Hypertension.Circulation 2018;137(22):2360-2370.

43. Tedford RJ, Mudd JO, Girgis RE, Mathai SC, Zaiman AL, Housten-Harris T, et al. Right ventricular dysfunction in systemic sclerosis-associated pulmonary arterial hypertension. Circ Heart Fail 2013:6(5):953-63.

44. Herve P, Lau EM, Sitbon O, Savale L, Montani D, Godinas L, et al. Criteria for diagnosis of exercise pulmonary hypertension. Eur Respir J. 2015; 46:728-37.

45. Lau EM, Godinas L, Sitbon O, Montani D, Savale L, Jaïs X, et al. Resting pulmonary artery pressure of 21-24 mmHg predicts abnormal exercise haemodynamics. Eur Respir J. 2016; 47:1436-44

46. Heresi GA, Minai OA, Tonelli AR, Hammel JP, Farha S, Parambil JG, Dweik RA. Clinical characterization and survival of patients with borderline elevation in pulmonary artery pressure. Pulm Circ 2016; 3: 916-925.

47. Oliveira RKF, Faria-Urbina M, Maron BA, Santos M, Waxman AB, Systrom DM. Functional impact of exercise pulmonary hypertension in patients with borderline resting pulmonary arterial pressure. Pulm Circ. 2017; 7:654-665.

This article is protected by copyright. All rights reserved. 